\title{
Atrioventricular valve repair in patients with functional single ventricle
}

\author{
Tomohiro Nakata, MD, ${ }^{\mathrm{a}}$ Yoshifumi Fujimoto, MD, ${ }^{\mathrm{b}}$ Keiichi Hirose, MD, PhD, ${ }^{\mathrm{b}}$ Yuko Tosaka, MD, PhD, \\ Yujiro Ide, MD, ${ }^{\mathrm{b}}$ Maiko Tachi, MD, ${ }^{\mathrm{b}}$ and Kisaburo Sakamoto, $\mathrm{MD}^{\mathrm{b}}$
}

Objective: We aimed to evaluate surgical repair of atrioventricular valve regurgitation in patients with functional single ventricle.

\begin{abstract}
Methods: The medical records of 65 consecutive patients with functional single ventricle who underwent atrioventricular valve repair between January 1999 and October 2008 were reviewed retrospectively. Their characteristics were as follows: median age, 9.5 months; median weight, $6.0 \mathrm{~kg}$; atrial isomerism, 31 patients; and hypoplastic left heart syndrome, 12 patients. Regurgitation was repaired at the palliative, Glenn, and Fontan stage in 21,29 , and 15 patients, respectively.
\end{abstract}

\begin{abstract}
Results: The overall survival was $79 \%$ and $70 \%$ at 1 and 5 years, respectively. The risk factors for mortality were age less than 3 months $(P<.001)$, body weight less than $4 \mathrm{~kg}(P<.001)$, hypoplastic left heart syndrome $(P=.001)$, concomitant Norwood $(P<.001)$, and the palliative stage $(P=.004)$ on the univariate analysis, and body weight less than $4 \mathrm{~kg}(P=.010$, hazard ratio, $9.8 ; 95 \%$ confidence interval, $1.7-55.6)$ on the multivariate analysis. Twenty patients underwent reoperation (repairs in 15; replacements in 5), and freedom from reoperation at 1 and 5 years was $69 \%$ and $57 \%$, respectively. Concomitant systemic-to-pulmonary shunt $(P=.040)$ was a risk factor for reoperation on the univariate analysis. Of the 48 survivors, 38 underwent Fontan completion, 7 underwent the Glenn procedure, and 3 are awaiting the Glenn procedure.
\end{abstract}

Conclusions: The midterm results of atrioventricular valve repair in patients with functional single ventricle were favorable; however, young and small patients, especially those with hypoplastic left heart syndrome, still had poor outcomes. (J Thorac Cardiovasc Surg 2010;140:514-21)

With improvements in treatment strategies, surgery, and management, the outcomes of patients with functional single ventricle (FSV) have improved dramatically. However, treatment of patients with FSV who have systemic atrioventricular valve (AVV) regurgitation remains a clinical challenge. Knowledge is lacking about such patients, because most related studies have focused on surgical technique, ${ }^{1-4}$ diagnosis, ${ }^{5,6}$ valve morphology, ${ }^{1,2}$ or surgical stage leading to Fontan completion. ${ }^{7-11}$ The purpose of this study was to evaluate a single institution's 10-year experience with the surgical repair of systemic AVV regurgitation in consecutive patients with FSV and to identify the factors associated with outcomes.

\footnotetext{
From the Department of Cardiovascular Surgery, ${ }^{\text {a }}$ Kyoto University Graduate School of Medicine, Kyoto, Japan; and Department of Cardiovascular Surgery, ${ }^{\mathrm{b}}$ Shizuoka Children's Hospital, Shizuoka, Japan.

Read at the Thirty-fifth Annual Meeting of the Western Thoracic Surgical Association, June 24-27, 2009, Banff, Alberta, Canada.

Disclosures: None.

Received for publication June 19, 2009; revisions received April 24, 2010; accepted for publication May 14, 2010; available ahead of print June 28, 2010.

Address for reprints: Kisaburo Sakamoto, MD, Department of Cardiovascular Surgery, Shizuoka Children's Hospital, 860 Urushiyama Aoi-ku, Shizuoka 420-8660, Japan (E-mail: sakamoto@jun.ncvc.go.jp).

$0022-5223 / \$ 36.00$

Copyright (c) 2010 by The American Association for Thoracic Surgery doi:10.1016/j.jtcvs.2010.05.024
}

\section{PATIENTS AND METHODS Study Design}

We retrospectively reviewed the medical records of all consecutive patients with FSV $(\mathrm{n}=65)$ who had AVV regurgitation and underwent AVV repair between January 1999 and October 2008 at Shizuoka Children's Hospital. This study was approved by the institutional review board of the hospital, and the need for patient consent was waived. We focused on systemic AVV repair and excluded tricuspid valve repair in patients with pulmonary atresia and intact ventricular septum or Ebstein anomaly, and closure of $1 \mathrm{AVV}$ orifice with or without patch in patients with both tricuspid and mitral valves. Our surgical indication for AVV regurgitation was "'moderate or more," regardless of initial repair or re-repair, and AVV repair was performed even in neonates; therefore, we had no contraindicated cases.

The medical, operative, angiographic, and echocardiographic data for all patients were reviewed. Information regarding their clinical status was obtained from the medical records and contact with the referring cardiologist.

\section{Echocardiographic Data}

The degree of regurgitation was assessed by routine preoperative and postoperative or predischarge transthoracic echocardiography. Each patient had postdischarge transthoracic echocardiographic examinations conducted at the cardiologists' discretion and as clinically indicated. Two-dimensional and color Doppler examinations were performed, and regurgitation was graded as follows: 0 , none; 1 , trivial; 2 , mild; 3 , moderate; and 4 , severe.

\section{Operative Techniques and Management}

To confirm the location and degree of regurgitation and to assess AVV morphology including leaflets and subvalvular tissues, precise preoperative transthoracic echocardiography was performed. We have routinely 


\section{Abbreviations and Acronym \\ $\mathrm{AVV}=$ atrioventricular valve \\ $\mathrm{CI} \quad=$ confidence interval \\ $\mathrm{FSV}=$ functional single ventricle \\ HLHS $=$ hypoplastic left heart syndrome \\ RAI = right atrial isomerism}

performed intraoperative transesophageal echocardiography since 2004, provided that the patient is aged more than 1 month, weighs more than $3.5 \mathrm{~kg}$, and does not have extracardiac total anomalous pulmonary venous connection, pulmonary venous obstruction, or an airway or esophageal anomaly. In young, small patients not satisfying these criteria, especially at the palliative stage, we tried to achieve hemodynamic stability intraoperatively; the sternum was left open, and transthoracic echocardiography was performed routinely in the intensive care unit.

AVV repair was performed through a median sternotomy, under cardiopulmonary bypass with mild-to-moderate hypothermia, and cardiac arrest using aortic crossclamping. The repair was performed by a single surgeon, excluding 1 emergency case of AVV re-repair. Our methods were as follows:

1. We dissected fully around the ventricle and did not suspend the pericardium ipsilateral to the apex (to move the ventricle freely). The pleural space ipsilateral to the apex was opened as necessary.

2. Although it is possible to approximate natural tension in the AVV intraoperatively, it is important to note that the plane of the AVV may be different under conditions of cardiac arrest (compared with normal beating-heart conditions). Thus, we try to reproduce the preoperative echocardiographic findings using careful and multiple traction sutures, without the use of retractors where possible, regardless of situs or apex.

3. The AVV was tested by saline injection into the ventricles.

4. De Vega annuloplasty, involving nonspecific reduction of all leaflets regardless of competency, was performed in the early study period. However, we believe that regurgitant AVV in patients with FSV is mostly caused by structural abnormalities, including abnormal clefts and commissures, dysplastic leaflets, and elongated or shortened chordae, ${ }^{1,2,10}$ especially in cases of atrial isomerism. ${ }^{12,13}$ Therefore, in later cases, we favored commissural annuloplasty and closure of abnormal clefts or commissures (leaflet apposition), ${ }^{6}$ attempting to preserve the normal or functional leaflets and commissures.

5. An annuloplasty ring was used for only adult-sized valves, and AVV replacement was not performed in any patient as the initial procedure.

Decisions regarding AVV repair were influenced by the patient's size. When reducing the annular diameter, an acceptable opening orifice must be maintained. Therefore, the diameter of opening orifice was measured and determined intraoperatively. We attempted to preserve the following opening orifice: $100 \%$ of the normal tricuspid valve annular diameter (calculated from Rowlatt and colleagues' modified equation ${ }^{14}$ ) at the palliative stage, $80 \%$ of the normal tricuspid valve annular diameter at the Glenn stage (cavopulmonary anastomosis including bidirectional Glenn, Kawashima procedures, and hemi-Fontan), and $80 \%$ of the normal mitral valve annular diameter at the Fontan stage. ${ }^{6}$ Additional pulmonary blood flow ${ }^{15}$ at the Glenn stage was avoided to prevent volume overloading. Some patients with unilateral pulmonary arterial hypoplasia require additional pulmonary blood flow. In these patients, we used new intrapulmonary-artery septation procedures, ${ }^{16}$ including unilateral cavopulmonary anastomosis, systemicto-pulmonary shunt, and septation between 2 blood sources with good results.
TABLE 1. Preoperative patient profiles

\begin{tabular}{|c|c|c|}
\hline Characteristic & $\mathbf{N}$ & $<\mathbf{3}$ mo \\
\hline Gender (female/male) & $31 / 34$ & $7 / 9$ \\
\hline \multicolumn{3}{|l|}{ Age at repair } \\
\hline Newborn & 12 & \\
\hline Infant $(<3 \mathrm{mo} />3 \mathrm{mo})$ & $4 / 21$ & \\
\hline$>1 \mathrm{y}$ & 28 & \\
\hline \multicolumn{3}{|l|}{ Primary diagnosis } \\
\hline Right atrial isomerism & 26 & 8 \\
\hline Hypoplastic left heart syndrome & 12 & 6 \\
\hline Corrected transposition of the great arteries & 5 & \\
\hline Univentricular heart & 5 & \\
\hline Left atrial isomerism & 5 & 1 \\
\hline Double-outlet right ventricle & 3 & \\
\hline Unbalanced common atrioventricular canal & 2 & \\
\hline Crisscross heart & 2 & \\
\hline Others & 5 & 1 \\
\hline \multicolumn{3}{|l|}{ Systemic AVV morphology } \\
\hline Common AVV & 35 & 9 \\
\hline Tricuspid valve & 20 & 6 \\
\hline Mitral valve & 2 & \\
\hline Both tricuspid and mitral valve & 8 & 1 \\
\hline \multicolumn{3}{|l|}{ Dominant ventricle morphology } \\
\hline Right & 40 & 12 \\
\hline Left & 8 & 3 \\
\hline Others & 17 & 1 \\
\hline \multicolumn{3}{|l|}{ Situs } \\
\hline Solitus & 32 & 7 \\
\hline Inversus & 2 & \\
\hline Ambiguous & 31 & 9 \\
\hline \multicolumn{3}{|l|}{ Apex } \\
\hline Right & 13 & 2 \\
\hline Left & 52 & 14 \\
\hline
\end{tabular}

$A V V$, Atrioventricular valve.

\section{Statistical Analyses}

End points were overall survival, AVV reoperation, and moderate or more recurrent AVV regurgitation. Prognostic variables examined include continuous variables (total cardiopulmonary bypass time, aortic crossclamping time) and categoric variables (gender, age $<3$ months, body weight $<4 \mathrm{~kg}$, primary diagnosis, AVV morphology, dominant ventricle morphology, situs, apex, degree of preoperative AVV regurgitation, repair procedure, single or multiple repair procedures, concomitant surgical procedure, and surgical stage leading to Fontan completion). AVV reoperation was also tested as a possible predictor of mortality.

Continuous variables are summarized as the median value and range or the mean \pm standard deviation as appropriate. Data from groups were compared with the Fisher's exact test, chi-square test, or Wilcoxon rank-sum test as appropriate. Actuarial survival, freedom from AVV reoperation, and freedom from AVV reoperation or moderate or more recurrent AVV regurgitation were estimated by the Kaplan-Meier method, and 95\% confidence intervals (CIs) were constructed around the curves according to Greenwood's formula.

These clinical variables were analyzed using the Cox regression hazard model for continuous variables and the log-rank test for categoric variables on univariate analysis. Variables with $P$ values of less than .1 on the univariate analysis were entered as candidates into the Cox model for multivariate analysis. Hazard ratios with $95 \%$ CIs were constructed for the significant multivariate predictors. The Dr SPSS II statistical software for Windows (SPSS, Inc, Chicago, Ill) was used for data analysis. 
TABLE 2. Timing of atrioventricular valve repair

\begin{tabular}{|c|c|c|c|c|c|c|c|c|}
\hline \multirow[b]{2}{*}{ Timing of repair } & \multirow[b]{2}{*}{$\mathbf{N}$} & \multirow[b]{2}{*}{$<3$ mo } & \multirow[b]{2}{*}{$<4 \mathbf{~ k g}$} & \multicolumn{5}{|c|}{ Primary diagnosis } \\
\hline & & & & HLHS & RAI & cTGA & LAI & Others \\
\hline \multicolumn{9}{|l|}{ Palliative stage } \\
\hline \multicolumn{9}{|l|}{ Initial palliation } \\
\hline Systemic-to-pulmonary shunt & 8 & 7 & 7 & & 6 & & & 2 \\
\hline Norwood procedure & 5 & 5 & 5 & 5 & & & & \\
\hline Pulmonary artery banding & 3 & 1 & 1 & & 2 & 1 & & \\
\hline Ventricle-to-pulmonary shunt & 1 & 1 & & & & & 1 & \\
\hline Interstage (before cavopulmonary anastomosis) & 4 & 1 & 2 & 2 & 2 & & & \\
\hline \multicolumn{9}{|l|}{ Glenn stage } \\
\hline Cavopulmonary anastomosis & 22 & 1 & 3 & 2 & 9 & 2 & 1 & 8 \\
\hline Interstage (before Fontan) & 7 & & & 1 & 3 & 2 & & 1 \\
\hline \multicolumn{9}{|l|}{ Fontan stage } \\
\hline Fontan & 11 & & 1 & 2 & 4 & & 2 & 3 \\
\hline After Fontan & 4 & & & & & & 1 & 3 \\
\hline Total & 65 & 16 & 19 & 12 & 26 & 5 & 5 & 17 \\
\hline
\end{tabular}

$c T G A$, Corrected transposition of the great arteries; $H L H S$, hypoplastic left heart syndrome; $L A I$, left atrial isomerism; $R A I$, right atrial isomerism.

\section{RESULTS}

\section{Patient Population}

During the study period, 65 consecutive patients with FSV who had AVV regurgitation underwent AVV repair. Patient demographic and morphologic variables are shown in Table 1. The timing of AVV repair is shown in Table 2, and the surgical procedures performed concomitant to AVV repair are listed in Table 3.

The median age at AVV repair was 9.5 months (range, 0 days -17 years), and the median body weight was $6.0 \mathrm{~kg}$ (range, 2.5-66.0 kg). The mean follow-up period was $37.5 \pm 37.1$ months, and follow-up was completed for all patients. Three patients underwent AVV repair at our institution before the study period, and 3 patients previously underwent AVV repair at other institutions. The mean cardiopulmonary bypass time was $218 \pm 62$ minutes. The mean aortic crossclamping time $(n=63)$ was $84 \pm 27$ minutes. In 2 patients, AVV repair was performed during induced ventricular fibrillation.

TABLE 3. Surgical procedures performed concomitant to atrioventricular valve repair

\begin{tabular}{lr}
\hline \multicolumn{1}{c}{ Concomitant surgical procedures } & $\mathbf{N}$ \\
\hline Pulmonary artery angioplasty & 24 \\
Intrapulmonary artery septation & 6 \\
Extracardiac TAPVC repair & 5 \\
Release of pulmonary venous stenosis & 5 \\
DKS anastomosis & 3 \\
ECMO & 3 \\
Release of ventricular outflow tract obstruction & 2 \\
Recoarctation repair & 2 \\
Others & 4 \\
\hline$D K S$, Damus-Kaye-Stansel; ECMO, extracorporeal membrane oxygenation; TAPVC, \\
total anomalous pulmonary venous connection.
\end{tabular}

Data regarding repair procedure were available for 63 patients $(97 \%)$ and are shown in Table 4 . Commissural annuloplasty $(81 \%)$ and closure of commissure or cleft (leaflet apposition) $(52 \%)$ were the predominant repair procedures. The number of patients who underwent single procedures was significantly higher in patients with hypoplastic left heart syndrome (HLHS) $(P=.003)$, age less than 3 months $(P=.005)$, and body weight less than $4 \mathrm{~kg}(P=.006)$, and significantly lower in the Glenn stage group $(P=.029)$ (Table 5).

\section{Survival}

Kaplan-Meier estimated survival after AVV repair was $79 \%(95 \%$ CI, 68-89) and 70\% (95\% CI, 58-82) at 1 and 5 years, respectively (Figure 1, A). The outcomes with regard to the timing of AVV repair and the patients' surgical stage are shown in Figure 2. There were 3 early deaths, 9 hospital deaths, and 5 late deaths. Of the 48 survivors, 38 underwent Fontan completion, 7 underwent the Glenn procedure, and 3 are awaiting the Glenn procedure.

Significant risk factors for mortality on the univariate analysis were as follows: age less than 3 months $(P<.001)$, body

TABLE 4. Atrioventricular valve repair procedures

\begin{tabular}{lcc}
\hline \multicolumn{1}{c}{ Procedures } & N & $<\mathbf{3 ~ m o}$ \\
\hline Commissural annuloplasty & 51 & 13 \\
Closure of commissure or cleft & 33 & 3 \\
Edge-to-edge repair & 19 & 4 \\
De Vega annuloplasty & 8 & 3 \\
Chordae shortening & 5 & 0 \\
Papillotomy & 5 & 0 \\
Artificial chordae & 2 & 0 \\
Annuloplasty ring & 1 & 0 \\
\hline
\end{tabular}


TABLE 5. Single or multiple procedures

\begin{tabular}{|c|c|c|c|c|c|c|}
\hline \multirow{2}{*}{$\begin{array}{l}\text { Primary } \\
\text { diagnosis }\end{array}$} & \multirow[b]{2}{*}{$\mathbf{N}$} & \multicolumn{2}{|c|}{ Operation record } & \multicolumn{2}{|c|}{$\begin{array}{l}\text { AVV repair } \\
\text { procedures }\end{array}$} & \multirow[b]{2}{*}{$P$} \\
\hline & & Unavailable & Available & Single & Multiple & \\
\hline RAI & 26 & 1 & 25 & 6 & 19 & \\
\hline HLHS & 12 & & 12 & 8 & 4 & .003 \\
\hline cTGA & 5 & & 5 & & 5 & \\
\hline $\begin{array}{l}\text { Univentricular } \\
\text { heart }\end{array}$ & 5 & & 5 & 1 & 4 & \\
\hline LAI & 5 & 1 & 4 & 1 & 3 & \\
\hline DORV & 3 & & 3 & 1 & 2 & \\
\hline $\begin{array}{c}\text { Unbalanced } \\
\text { CAVC }\end{array}$ & 2 & & 2 & & 2 & \\
\hline $\begin{array}{c}\text { Criss cross } \\
\text { heart }\end{array}$ & 2 & & 2 & & 2 & \\
\hline Others & 5 & & 5 & 1 & 4 & \\
\hline \multicolumn{7}{|l|}{ Surgical stage } \\
\hline $\begin{array}{l}\text { Palliative } \\
\text { stage }\end{array}$ & 21 & & 21 & 9 & 12 & \\
\hline Glenn stage & 29 & 1 & 28 & 4 & 24 & .029 \\
\hline Fontan stage & 15 & 1 & 14 & 5 & 9 & \\
\hline Age $<3$ mos & 16 & & 16 & 9 & 7 & .005 \\
\hline $\begin{array}{l}\text { Body weight } \\
<4 \mathrm{~kg}\end{array}$ & 19 & & 19 & 10 & 9 & .006 \\
\hline
\end{tabular}

weight less than $4 \mathrm{~kg}(P<.001)$, HLHS $(P=.001)$ (Figure 1, $B)$, concomitant Norwood procedure $(P<.001)$, and palliative stage $(P=.004)$ (Figure $1, C)$. By using multivariate Cox regression analysis, the one significant risk factor for mortality was body weight less than $4 \mathrm{~kg}(P=.010$, hazard ratio, 9.8; 95\% CI, 1.7-55.6).

\section{Atrioventricular Valve Regurgitation and Reoperation}

Postoperative echocardiography was not performed in 2 of the 3 patients with early death after the initial AVV repair (these 2 patients were excluded from the analysis of freedom from AVV reoperation, and analysis of freedom from AVV reoperation or moderate or more recurrent AVV regurgitation). Postoperative echocardiography was not performed in 1 patient with early death after AVV re-repair. We compared and evaluated both the preoperative and postoperative regurgitation grade data of the remaining patients. In the patients who underwent AVV reoperation during the same hospitalization $(n=4)$, we evaluated the final data obtained before reoperation. Two of these were patients with HLHS ( 1 at the Glenn stage, and 1 at the Fontan stage; both treated in the early study period), and 2 were patients with right atrial isomerism (RAI) (both at the palliative stage).

The patients who underwent AVV repair had a preoperative regurgitation grade of $3.4 \pm 0.5$, which decreased significantly to $2.2 \pm 1.0$ on the postoperative or predischarge examina- tions $(\mathrm{n}=63 ; P<.001)$. Twenty patients underwent AVV reoperation (repairs, 15; replacements, 5). The median interval from AVV repair to reoperation was 5.9 months (range, 0.2-47.2). The patients who underwent AVV re-repair had a preoperative regurgitation grade of $3.4 \pm 0.5$, which decreased significantly to $2.2 \pm 0.8$ in the postoperative or predischarge examinations $(\mathrm{n}=14 ; P<.001)$. Of the 46 survivors without prosthetic valves, the latest follow-up echocardiographic regurgitation grade was $1.9 \pm 1.0$.

Freedom from AVV reoperation $(\mathrm{n}=63)$ at 1 and 5 years was $69 \%(95 \% \mathrm{CI}, 56-82)$ and $57 \%(95 \% \mathrm{CI}, 42-72)$, respectively (Figure 1,D). Freedom from AVV reoperation or moderate or more recurrent AVV regurgitation $(\mathrm{n}=63)$ at 1 and 5 years was $51 \%(95 \% \mathrm{CI}, 38-64)$ and $39 \%(95 \% \mathrm{CI}$, 24-54), respectively (Figure 1, G). The cause of all reoperations was regurgitation, and no reoperation was performed because of stenosis.

A significant risk factor on the univariate analysis for AVV reoperation was concomitant systemic-to-pulmonary shunt $(P=.040)$, whereas significant risk factors for AVV reoperation or moderate or more recurrent AVV regurgitation were age less than 3 months $(P=.021)$, body weight less than $4 \mathrm{~kg}$ $(P=.010)$, concomitant systemic-to-pulmonary shunt $(P<.001)$, and the palliative stage $(P=.008)$ (Figure $1, I)$. On multivariate Cox regression analysis, none reached statistical significance.

There was no significant morphologic determinant on postoperative AVV analysis. RAI was more commonly associated with AVV reoperation or moderate or more recurrent AVV regurgitation, but did not reach statistical significance $(P=.123)$ (Figure $1, H)$.

\section{Atrioventricular Valve Repair in Neonatal or Early Infant Period}

Sixteen patients underwent AVV repair in the neonatal $(n=12)$ or early infant $(n=4)$ periods. Patient demographic and morphologic variables are shown in Table 1. Four patients $(25 \%)$ were diagnosed prenatally, and 12 patients $(75 \%)$ required preoperative intubation and respirator control. The data regarding repair procedure are shown in Table 4.

Kaplan-Meier estimated survival of patients aged less than 3 months was $59 \%(95 \% \mathrm{CI}, 34-85)$ at 1 year and $34 \%(95 \% \mathrm{CI}, 8-60)$ at 5 years, whereas that of patients aged more than 3 months was $85 \%(95 \%$ CI, 74-95) at 1 year and $82 \%(95 \% \mathrm{CI}, 70-93)$ at 5 years $(P<.001)$. Patient deaths included the following: 1 early death (necrotizing cholecystitis), 6 hospital deaths (bilateral and multiple recurrent pulmonary venous obstruction, 2; renal failure, 1 ; arrhythmia, 1; airway bleeding, 1 ; mediastinitis, 1), and 2 late deaths ( 1 infection and 1 sudden death). Five patients underwent AVV reoperation (repairs, 4; replacement, 1).

Of the 7 survivors, 3 underwent AVV re-repair, and none had prosthetic valves. The latest follow-up echocardiographic 
Survival

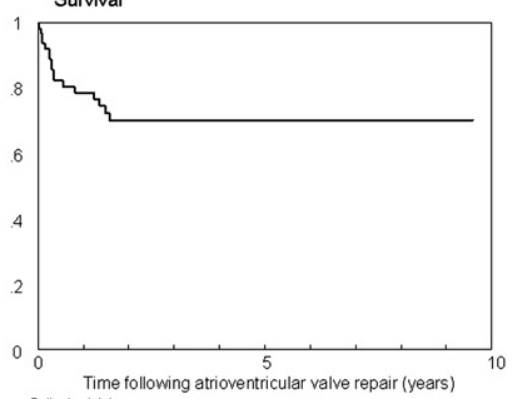

$\begin{array}{lll}\text { Patients at risk } & \text { (25) } & \text { (19) }\end{array}$

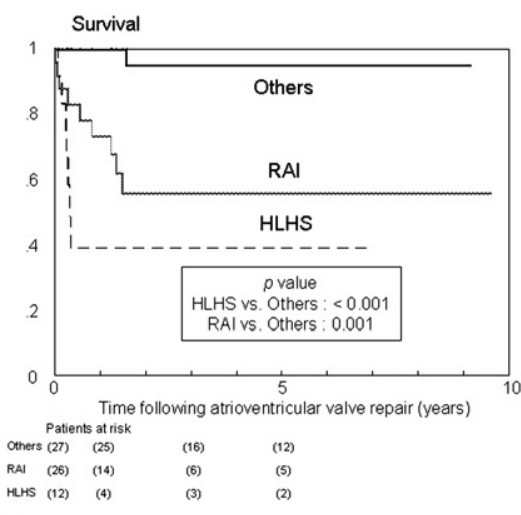

B

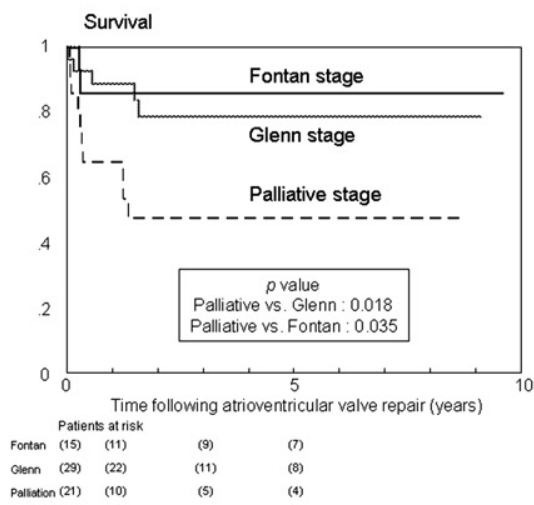

C
Freedom from atrioventricular valve reoperation

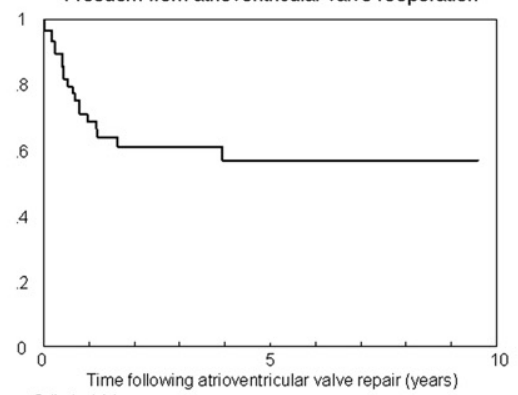

D ${ }^{\text {Patients at risk }}{ }^{(31)}$ (16)

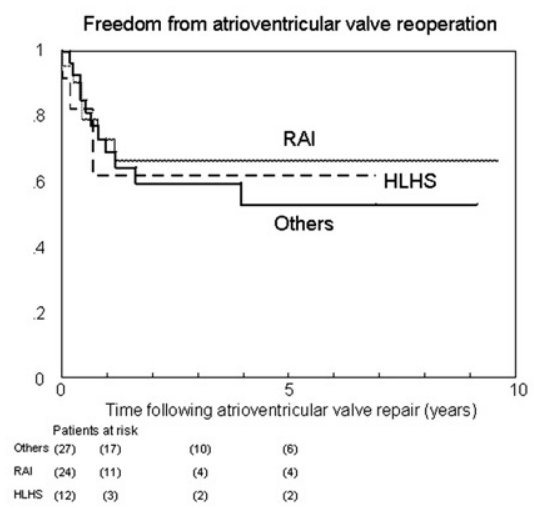

E

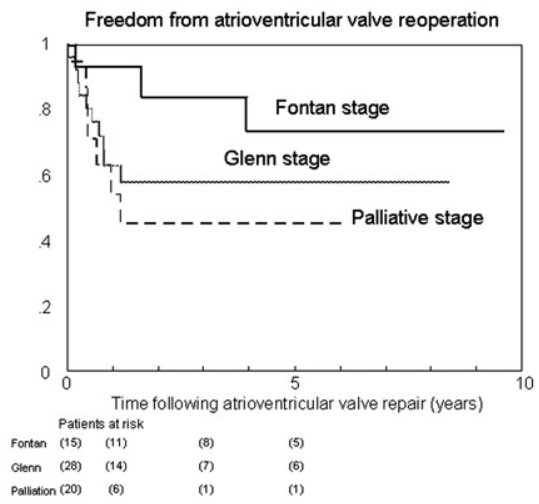

$\mathbf{F}$

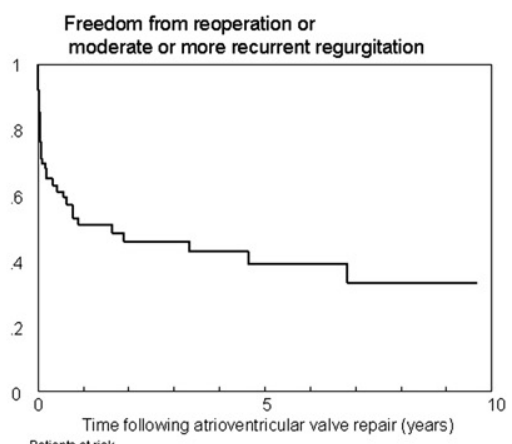

G $\begin{array}{lll}\begin{array}{l}\text { Patients at risk } \\ \text { (63) (24) }\end{array} & \text { (14) }\end{array}$

FIGURE 1. Kaplan-Meier estimated survival: overall (A), according to diagnosis (B), and according to the surgical stage (C). Freedom from AVV reoperation: overall (D), according to diagnosis $(\mathrm{E})$, and according to the surgical stage $(\mathrm{F})$. Freedom from reoperation or moderate or more recurrent regurgitation: overall $(\mathrm{G})$, according to diagnosis $(\mathrm{H})$, and according to the surgical stage (I). The number of patients at risk at $0,1,3$, and 5 years is shown. HLHS, Hypoplastic left heart syndrome; RAI, right atrial isomerism.

regurgitation grade was $1.7 \pm 0.9$. Four patients underwent Fontan completion, 1 patient underwent the Glenn procedure, and 2 patients are awaiting the Glenn procedure.

\section{Fontan Completion}

Forty-one patients underwent Fontan completion with 1 hospital death (HLHS, cardiac dysfunction) and 2 late deaths (HLHS, cardiac dysfunction; RAI, infection). Eight patients underwent Fontan completion without interim cavopulmonary anastomosis. The median age at Fontan completion was 29.7 months (range, 7.0-204.9 months), and the median body weight was $10.6 \mathrm{~kg}$ (range, $3.8-66.0 \mathrm{~kg}$ ). Fenestrations were placed in 5 patients; of these patients, a single-lung Fontan procedure (for obstruction of the unilateral pulmonary veins) was performed in 2 patients. Follow-up cardiac catheterizations were performed in 33 


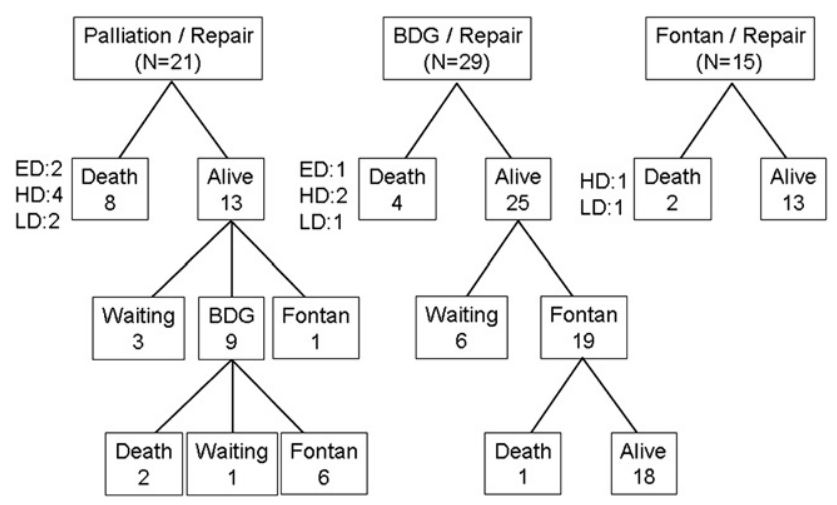

FIGURE 2. Outcomes of patients with FSV after AVV repair. $B D G$, Bidirectional Glenn; $E D$, early death; $H D$, hospital death; $L D$, late death.

patients after Fontan completion (we evaluated the latest data). The interval between Fontan completion and the latest follow-up cardiac catheterization was $38.5 \pm 33.8$ months. The hemodynamic variables were as follows: central venous pressure, $12.9 \pm 2.6 \mathrm{~mm} \mathrm{Hg}$; cardiac index, $3.0 \pm 0.7 \mathrm{~L} /$ $\mathrm{min} / \mathrm{m}^{2}$; ejection fraction, $54.5 \% \pm 12.4 \%$; saturation, $92.9 \% \pm 4.9 \%$. At the latest follow-up, 2 patients who underwent single-lung Fontan procedure were in New York Heart Association class II and III, and the remaining 36 patients were in class I.

\section{DISCUSSION}

Treatment of patients with FSV has improved in recent years. However, significant systemic AVV regurgitation is reportedly a risk factor for mortality, particularly with a diagnosis of HLHS, RAI, or heterotaxy syndrome. ${ }^{17-19}$ There have been few reports on consecutive FSV patients with AVV regurgitation and no reports on AVV repair in these patients. Thus, the risk factors influencing their outcomes remain poorly understood. We were able to consider all aspects of these patients, because there were no contraindications, exclusions, or initial valve replacement cases.

The current surgical goal for these patients is staged Fontan completion. Some institutions consider heart transplantation for these patients, ${ }^{4,5-8-11}$ but this is not possible in Japan, where pediatric heart transplantation is prohibited. Further, although it has been shown that AVV replacement can be performed in patients with FSV with acceptable morbidity and mortality, ${ }^{4}$ it is preferable to avoid the use of prosthetic valves in growing patients.

In our 10-year experience, the Kaplan-Meier estimated survival was $79 \%$ and $70 \%$ at 1 and 5 years, respectively. Our results seem satisfactory considering the disease severity in our patient population (newborn, $18 \%$; RAI, $40 \%$; HLHS, $18 \%$; the palliative stage, $32 \%$ ).

Some reports have mentioned a size limitation of the AVV orifice reduced by surgical repair in patients with FSV. ${ }^{1,2}$ However, blood flow through the AVV can reasonably be expected to be different at each surgical stage; therefore, we tried to confirm and determine the appropriate diameter of opening orifice intraoperatively. ${ }^{6}$ Normal-sized tricuspid valves in patients with classic HLHS (aortic and mitral atresia) can tolerate the total cardiac output of Norwood circulation; therefore, $100 \%$ of the normal tricuspid valve annular diameter is enough at the palliative stage. Eighty percent of the normal tricuspid valve annular diameter is equal to $95 \%$ to $99 \%$ of the normal mitral valve annular diameter (calculated from Rowlatt and colleagues' modified equation ${ }^{14}$ ). The bidirectional Glenn without additional pulmonary flow creates volume unloading; therefore, approximately $100 \%$ of the normal mitral valve annular diameter is enough at the Glenn stage. We have used the limitation of $80 \%$ of the normal mitral valve annular diameter for mitral valve repair in patients with 2 ventricles without major problems. Cardiac output is limited in Fontan circulation without fenestration and determined primarily by the pulmonary vascular bed ${ }^{20}$; therefore, $80 \%$ of the normal mitral valve annular diameter is enough at the Fontan stage. In addition, collateral vessel formation after the Glenn procedure may increase volume loading gradually. ${ }^{21,22}$ However, it may not occur after the Fontan completion without fenestration. Therefore, we differentiated the Glenn stage from the Fontan stage for the diameter. Because there was no reoperation for valve stenosis, our size limitation standard seems reasonable, reliable, and reproducible.

The choice of repair procedure for patients with FSV is an important issue. AVV morphology varies widely, especially with atrial isomerism, ${ }^{12,13}$ and the decision regarding the repair procedure must be based on the preoperative and intraoperative morphologic findings. Therefore, it is most important to reproduce the preoperative echocardiographic findings of the AVV with a reasonable operative field; otherwise, the surgeon may repair an area that has no regurgitation preoperatively, and the AVV may be deformed. We prefer commissural annuloplasty and closure of clefts or commissures (leaflet apposition) but cannot prove the superiority of these repair procedures by statistical analysis. However, because the normal or functional leaflets and commissures can be preserved using these techniques, we believe that they are superior to the De Vega annuloplasty in terms of allowing future AVV rerepair, preventing the need for AVV replacement, and reducing the size limitation at each surgical stage.

The risk factors for mortality were age less than 3 months, body weight less than $4 \mathrm{~kg}$, HLHS, concomitant Norwood procedure, and the palliative stage on the univariate analysis, and body weight less than $4 \mathrm{~kg}$ on the multivariate analysis. Patients with low body weight have small valves, limited choice of repair procedures, and overall fragility. To summarize these risk factors in plain language, young and small patients with FSV, especially those with HLHS, have poor outcomes.

We have reported the first case series of AVV repairs for neonates and early infants. Our results seem reasonable, but not satisfactory. Overall fragility makes AVV repair difficult 
in such small patients. In fact, we observed dehiscence of the repair suture for the edge of the leaflet in an autopsy case in the early study period. Since this experience, we performed a commissural annuloplasty procedure and avoided suturing the edge of the leaflet to achieve sufficient strength in the repair point in such small patients. It may be difficult to eliminate AVV regurgitation completely in the initial repair. Therefore, we tried to perform AVV repair several times to achieve satisfactory control of the regurgitation ("staged AVV repair'). We reduced the valve size limitation at each surgical stage and increased the range of repair procedures, including edge-to-edge repair. More than half of the causes of death in such patients were unrelated to AVV regurgitation or cardiac dysfunction. Therefore, we believe that AVV regurgitation can be controlled with staged intervention.

We identified concomitant systemic-to-pulmonary shunt as the only significant risk factor for AVV reoperation on the univariate analysis. The finding that volume overloading in systemic-to-pulmonary shunt circulation is not compatible with AVV repair is not surprising. Therefore, early bidirectional Glenn is recommended. The median age of such patients who underwent bidirectional Glenn was 6.1 months.

Early in the study period, we performed the Fontan completion with lateral tunnel during infancy (without interim cavopulmonary anastomosis), ${ }^{23}$ even with AVV regurgitation, if the patients were small and there was a need to avoid volume overloading. However, the volume reduction of the Glenn procedure has been shown to be effective in high-risk Fontan candidates ${ }^{24}$ and has been widely adopted. Therefore, because there was 1 hospital death and 1 late death after Fontan completion (both HLHS cases with tricuspid regurgitation), we adopted an interim Glenn procedure, in which volume unloading is achieved during infancy, after which an extracardiac conduit Fontan procedure was performed with excellent results. ${ }^{25}$

Our surgical indication for AVV regurgitation was " moderate or more." However, Mahle et $\mathrm{al}^{10}$ reported that AVV regurgitation improves in some patients after a bidirectional Glenn procedure. Their report was based on nonrandomized study; therefore, we could not evaluate the positive effect on AVV regurgitation after volume unloading of a bidirectional Glenn procedure. Moreover, it is difficult to perform a randomized study, partially because of the wide variety of AVV in patients with FSV.

To our knowledge, no previous study has shown the postoperative hemodynamic variables after AVV repair and Fontan completion. In our series, the hemodynamic variables were excellent considering the disease severity in our patient population. Furthermore, our patients had maintained good physical status.

\section{Study Limitations}

This study has several limitations. It is a retrospective and nonrandomized study with a relatively small number of patients. Further, the mean follow-up period was only $37.5 \pm 37.1$ months. Therefore, a larger number of patients and longer follow-up are required.

\section{CONCLUSIONS}

The midterm results of the surgical repair for AVV regurgitation in patients with FSV were favorable. With aggressive AVV repair, cardiac function can be maintained effectively. However, young and small patients with FSV, especially those with HLHS, still have poor outcomes; therefore, more efforts are required to improve their midterm results.

The authors thank Dr Shiro Tanaka for statistical advice and review of the statistical analysis in this study.

\section{References}

1. Kanter KR, Forbess JM, Fyfe DA, Mahle WT, Kirshbom PM. De Vega tricuspid annuloplasty for systemic tricuspid regurgitation in children with univentricular physiology. J Heart Valve Dis. 2004;13:86-90.

2. Ando M, Takahashi Y. Edge-to-edge repair of common atrioventricular or tricuspid valve in patients with functionally single ventricle. Ann Thorac Surg. 2007; 84:1571-6.

3. van Son JA, Walther T, Mohr FW. Patch augmentation of regurgitant common atrioventricular valve in univentricular heart. Ann Thorac Surg. 1997;64:508-10.

4. Mahle WT, Gaynor JW, Spray TL. Atrioventricular valve replacement in patients with a single ventricle. Ann Thorac Surg. 2001;72:182-6.

5. Ohye RG, Gomez CA, Goldberg CS, Graves HL, Devaney EJ, Bove EL. Tricuspid valve repair in hypoplastic left heart syndrome. J Thorac Cardiovasc Surg. 2004; 127:465-72.

6. Ota N, Fujimoto Y, Hirose K, Tosaka Y, Nakata T, Ide Y, et al. Improving results of atrioventricular valve repair in challenging patients with heterotaxy syndrome. Cardiol Young. 2010;20:60-5.

7. Imai Y, Takanashi Y, Hoshino S, Terada M, Aoki M, Ohta J. Modified Fontan procedure in ninety-nine cases of atrioventricular valve regurgitation. $J$ Thorac Cardiovasc Surg. 1997;113:262-8

8. Sallehuddin A, Bulbul Z, Otero F, Al Dhafiri K, Al-Halees Z. Repair of atrioventricular valve regurgitation in the modified Fontan procedure. Eur J Cardiothorac Surg. 2004;26:54-9.

9. Kerendi F, Kramer ZB, Mahle WT, Kogon BE, Kanter KR, Kirshborn PM. Perioperative risk and outcomes of atrioventricular valve surgery in conjunction with Fontan procedure. Ann Thorac Surg. 2009;87:1484-9.

10. Mahle WT, Cohen MS, Spray TL, Rychik J. Atrioventricular valve regurgitation in patients with single ventricle: impact of the bidirectional cavopulmonary anastomosis. Ann Thorac Surg. 2001;72:831-5.

11. Mavroudis C, Stewart RD, Backer CL, Deal BJ, Young L, Franklin WH. Atrioventricular valve procedures with repeat Fontan operation: influence of valve pathology, ventricular function, and arrhythmias on outcome. Ann Thorac Surg. 2005;80:29-36.

12. Uemura H, Ho SY, Anderson RH, Yagihara T. The structure of the common atrioventricular valve in hearts having isomeric atrial appendages and double inlet ventricle. J Heart Valve Dis. 1998;7:580-5.

13. Kawahira Y, Kishimoto H, Kawata H, Ikawa S, Ueda H, Nakajima T, et al. Morphologic analysis of common atrioventricular valves in patients with right atrial isomerism. Pediatr Cardiol. 1997;18:107-11.

14. Rowlatt UF, Rimoldi HJ, Lev M. The quantitative anatomy of the normal child's heart. Pediatr Clin North Am. 1963;10:499-588.

15. Cleuziou J, Schreiber C, Cornelsen JK, Horer J, Eicken A, Lange R. Bidirectional cavopulmonary connection without additional pulmonary blood flow in patients below the age of 6 months. Eur J Cardiothorac Surg. 2008;34:556-62.

16. Sakamoto K, Ikai A, Fujimoto Y, Ota N. Novel surgical approach 'intrapulmonary-artery septation' for Fontan candidates with unilateral pulmonary arterial hypoplasia or pulmonary venous obstruction. Interact Cardiovasc Thorac Surg. 2007;6:150-4

17. Sano S, Huang SC, Kasahara S, Yoshizumi K, Kotani Y, Ishino K. Risk factors for mortality after the Norwood procedure using right ventricle to pulmonary artery shunt. Ann Thorac Surg. 2009;1:178-86. 
18. Hashmi A, Abu-Sulaiman R, McCrindle BW, Smallhorn JF, Williams WG, Freedom RM. Management and outcomes of right atrial isomerism: a 26-year experience. J Am Coll Cardiol. 1998;31:1120-6.

19. Anagnostopoulos PV, Pearl JM, Octave C, Cohen M, Grussner A, Wintering E, et al. Improved current era outcomes in patients with heterotaxy syndromes. Eur J Cardiothorac Surg. 2009;35:871-8.

20. Gewillig MH, Lundstorm UR, Bull C, Wyse RK, Deanfield JE. Experience responses in patients with congenital heart disease after Fontan repair: patterns and determinants of performance. J Am Coll Cardiol. 1990;15:1424-32.

21. Berdat PA, Belli E, Lacour-Gayet F, Planche C, Serraf A. Additional pulmonary blood flow has no adverse effect on outcome after bidirectional cavopulmonary anastomosis. Ann Thorac Surg. 2005;79:29-37.
22. Gray RG, Altmann K, Mosca RS, Prakash A, Williams IA, Quaegebeur JM, et al. Persistent antegrade pulmonary blood flow post-Glenn does not alter early post-Fontan outcomes in single-ventricle patients. Ann Thorac Surg. 2007;84: 888-93.

23. Pizarro C, Mroczek T, Gidding SS, Murphy JD, Norwood WI. Fontan completion in infants. Ann Thorac Surg. 2006;81:2243-9.

24. Tanoue Y, Sese A, Ueno Y, Joh K, Hijii T. Bidirectional Glenn procedure improves the mechanical efficiency of a total cavopulmonary connection in highrisk Fontan candidates. Circulation. 2001;103:2176-80.

25. Ikai A, Fujimoto Y, Hirose K, Ota N, Tosaka Y, Nakata T, et al. Feasibility of the extracardiac conduit Fontan procedures in patients weighing less than 10 kilograms. J Thorac Cardiovasc Surg. 2008;135:1145-52. 